\title{
Groups and facilitators within problem structuring processes
}

\author{
$\mathrm{S} \mathrm{Bell}^{1 *}$ and S Morse ${ }^{2}$ \\ ${ }^{1}$ Open University, Milton Keynes, UK; and ${ }^{2}$ University of Surrey, Guildford, Surrey, UK
}

In problem structuring methods, facilitators often ask of themselves questions such as: what makes a 'good' problem structuring group (PSG) and indeed what does 'good' mean? How can group dynamics be improved and does it matter in terms of the quality of the problem structuring that that group engages in? On the surface these questions seem to be straightforward. Indeed, those who have helped facilitate many participatory workshops will think they intuitively know the answers to these questions; they can, from their professional practice, 'feel' which PSGs are doing well and producing novel insights and those which are functioning less well and perhaps generating something that is less imaginative and more routine as a consequence. The intuitive, practice-learned insight will depend upon a rich array of visual signals that become more obvious with experience. This paper asks whether there is value in being much more open and analytical about these questions and answers. If so, then how can we make the unwritten processes and outcomes of PSGs written? Indeed, open to whom? Finally, how much of any insights learned by facilitators should be shared with those engaged in workshops?

Journal of the Operational Research Society (2013) 64, 959-972. doi:10.1057/jors.2012.110

Published online 3 October 2012

Keywords: facilitation; workshops; problem structuring methods

\section{Introduction}

It is a truism that group dynamic is an important factor in what problem structuring groups or PSGs can achieve when it comes to structuring problems. Anyone who has been involved as a participant or facilitator of group work geared towards problem structuring will readily testify to the importance of such dynamics. If the dynamic is poorif people do not 'relate to each other' or if there are sources of friction - then members of the team may opt out of the process, thereby leaving it to a sub-group or even an individual to do the work, or the outcome of the activity may be disjointed. Thus, the problem structuring may either be a reflection of what one person or a small subgroup thinks is important or result in a fractured analysis that lacks coherence. Facilitators of the process can, of course, help resolve some of the tensions that may be at play, but much can depend upon their experience and inclination. A significant question here is: How can group 'performance' be improved and what role can the facilitator play? The obvious and somewhat banal answer, of course, is that the facilitator is present to facilitate the process, but allied to this is the question as to whether it matters in terms of the quality of the problem structuring

\footnotetext{
*Correspondence: $S$ Bell, Communications and Systems Department, Faculty of Mathematics, Computing and Technology, Open University, Milton Keynes MK7 6AA, UK.

E-mail: s.g.bell@open.ac.uk
}

that that group engages in. On the surface these two questions appear to be very straightforward, and facilitators will often think they intuitively know the answers. They can, from their professional practice, 'feel' which groups are doing well and producing novel insights and those which are functioning less well and perhaps generating something that is less imaginative and more routine as a consequence. They will sense how they can intervene (or not) to help keep the energy in the room. They will also have a view on whether an analysis is weak or strong and be able to link that to what they have observed of the group dynamic. The intuitive, practicelearned insight will depend upon a rich array of visual and atmospheric signals that become easier to read with experience. Thus, a facilitator with a rich store of practice will be able to identify signs of friction and harmony, of hard work and focus, of dominance, of tiredness, of 'soft' and qualitative variation and so on. More importantly, a facilitator with many years practice will feel confident to change the pace of the process or introduce 'tweaks' to enhance energy. All of this represents a mysterious, unwritten and little discussed (at least in much of the academic literature) matrix of instinctive solutions and puzzles. These questions and answers are readily shared and dissected among practitioners when they meet, often illustrated with examples, but often the narratives are not written - they are spoken - thus forming an unrecorded or 'acroamatic' record. 
This paper asks whether there is value in being much more reflective and analytical about these questions and answers. If so, then how can we make the unwritten processes and rules of PSG work written? To whom should such insights be available? Added to all of the above is how much of any insights should be shared with those engaged in the workshop? Do participants have a 'right' to know what their facilitators think during the workshop, even if this may be interpreted as being critical? However, it has to be stressed that this is a complex field, which a paper as short as this cannot hope to give full justice to. Hence, to some extent we raise more questions rather than provide all the answers. It should also be noted that we are specifically referring to PSGs rather than any group activity. The distinctions are blurred, of course, as groups (even transient ones) exist for a purpose and thus have a goal, but PSGs by definition are purposely orientated and focussed upon the analysis of a situation and the suggestion of action to help address any perceived problems that emerge out of the analysis.

In the following sections we will:

- provide some of the intellectual background to problem structuring in groups, giving some indication of where we have come from in order to gain a better appreciation of the territory. In this review we focus on the Operational Research (OR), psychodynamic and systems domains.

- Following this we expound upon the Triple Task Method (TTM), which we have employed. We show how we have employed the approach in a problem structuring context and describe major features and outcomes.

- Finally, we discuss lessons learned and provide some tentative answers to the questions set out above.

\section{Experiences of problem structuring with groups}

Others have exhaustively trawled the literature on group development (Smith, 2001). Rightly, Lewin, with his defining work, gave us the term 'group dynamics' (Lewin, 1947). The idea that groups had their own formative processes and that these could be understood and managed became something of a cause celeb in the literature. Lewin's thinking around how group minds could be unfrozen, changed and frozen again led to a series of developments from Tuckman's stages model (Tuckman, 1965; Tuckman and Jensen, 1977) - which is famous for giving us notions of 'forming', 'storming', 'norming' and 'performing' in problem assessment and structuring, and which formed the basis of the Linear model of group development (Smith, 2001, p 17). The Linear model assumes a 'stages' development approach to group development. Building from this, Fisher's notion of 'decision emergence'
(Fisher, 1970) enriched the group literature, and this can then be seen to have further impacts through to more contemporary models such as Morgan et al's TEAM model (Morgan et al, 1994) and Gersick's Punctuated Equilibrium' (Gersick, 1991):

The model resulting from this research was based on the observation that teams alternated between periods of stasis and long periods of inertia that were "punctuated by concentrated revolutionary periods of quantum change.

(Smith, 2001, p 35)

On the way, in the development of group thinking understanding, there have been noticeable splits in the practitioner base. Bion certainly seems to have been instrumental in the further development of the psychodynamic model (Bion, 1961). This in turn has had a rich expression in the works of professionals working in the psychodynamic traditions - such as the Tavistock and Bayswater Institutes (http://www.tavinstitute.org/and http://bayswaterinst.org/index.html). On the other hand, group thinking in problem structuring has also fed into the systems thinking movement as exemplified in the work of Bateson and, more recently, Maturana (Bateson, 1972; Maturana and Varela, 1992; Maturana, 1997).

More central to the focus of the OR community, Sims et al (1981) provided some early leads to the problem structuring capacities of teams. Indeed, the authors clearly defined many issues facing team problem structuring and disincentives for facilitators working with such groups. Sims and Eden also saw a key issue for Operational Researchers when it comes to group work, arguing that the researcher could "encompass a facilitator role within their expert problem structuring role rather than to become behavioural science consultants' (Sims et al, 1981, p 365) - this is not such a concern for those working with groups, but in other disciplines. This concern over the role of the practitioner is to some extent picked up by Pidd (1988), who, although writing in the domain of problem structuring and implementation, considered that there was a need at the time to 'legitimate non-scientific behaviour by practitioners' (Pidd, 1988, p 121). Pidd further argued that 'tangible and intangible factors are equally important in achieving successful implementation' (Pidd, 1988, p 121 (our emphasis)), a point key to this paper and which we will discuss in more detail shortly.

Harmon and Rohrbaugh (1990) worked with large sample groups and considered the role and function of feedback for groups-most specifically of interest in terms of the current paper, they were concerned with the function of feedback for individual and collective performance. Their reflection that feedback enhances learning and consensus is perhaps not too surprising. Bostrom et al (1993) evidenced the power and value of 
good facilitation in problem structuring, and Phillips and Phillips (1993) further this point, showing the value of the facilitator with the emotional as well as the rational problem structuring aspect of such work. Working from the OR side of the group working process, the value and purpose of information and communication technologies (ICT) in group work begins to emerge as a strong thread (Beise et al, 1999). However, Phillips and Phillips also note the power of facilitation:

We believe that through the creative potential of FWGs (Facilitated Work Groups), it is often possible to transform conflict into win-win situations. Without compromise, both organizational and individual objectives can be achieved. But even when this is not possible, effective organizational solutions can often be found in FWGs that are more satisfactory than anything proposed by an individual working alone. (Phillips and Phillips, 1993, p 548).

The value of the facilitation process for individual, group and collective is now clearly established (Huxham and Cropper, 1994; McFadzean and Nelson, 1998; Morton et al, 2007), and the requisite skills and essential inputs of the facilitator in contexts of systemic interventions have been addressed in detail (Ackermann, 1996; Nutt, 2002). The OR community continued to consider not just 'what' groups do but 'how they do it'. Andersen and Richardson (1997) expressed their focus as follows:

we are interested in how the members of the group modelbuilding team improvise. How do they interact with one another and with the client group as the game plan evolves? (Andersen and Richardson, 1997, p 126)

The OR community have traditionally discoursed in detail about the methodologies used in various forms of intervention and the issue of multi-disciplinarity in problem structuring (in the group facilitation domain, see, for example, Robinson, 2001; Taket, 2002; Mingers and Rosenhead, 2004; Rosenhead, 2006; Morton et al, 2007); however, our focus remains around the nature of the facilitation process itself and how outcomes are achieved. Papamichail et al (2007) have provided more insights into the importance of the idiosyncratic tendencies of the facilitator, and Franco et al (Franco and Montibeller, 2010; Franco and Rouwette, 2011) have explored the value of facilitation, and critically:

While the facilitated modelling literature recognises the importance of the group process within facilitated modelling workshops, published empirical research rarely examines their dynamic nature. (Franco and Rouwette, 2011, p 164)

Franco and Rouwette identify a 'gap' in the current literature. They suggest that the adoption of their approach as a lens would:

serve the purpose of 'unpacking' the richness and complexity of FM (Facilitated Modelling) approaches while, at the same time, systematically and rigorously testing their practical impact. (Franco and Rouwette, 2011, p 176)

In terms of group work, both the psychodynamic and $\mathrm{OR} /$ systems traditions have taken key learning from the literature and developed complex and interesting group working training products. The systems tradition is perhaps the more familiar of the two to most practitioners in the sense that the role of the facilitator is unambiguously set out to guide and encourage the groups in what is after all their analysis of the problem. Thus, in this tradition it is the outputs of the group work that is the goal, and process is only important as the means to that goal. The facilitator may be contracted to help deliver these outputs within a defined time frame. Hence, it may make use of approaches such as Rich Pictures (RPs) to allow groups to get to know each other in an informal manner (Avison et al, 1992; Lewis, 1992; Carrizosa, 2002; Campbell Williams, 1999), but it does not attempt to explore this in a psychological manner. The facilitator can intervene in various ways to help address 'issues' that might emerge, although care does need to be taken. It is not inconceivable that intervention by a facilitator can distort group function and consciously or unconsciously 'lead' them down roads set by the facilitator. This is especially so if the facilitator feels under pressure in terms of timely delivery (workshop may last for a day or perhaps less) or ensuring that what emerges is in tune with the funder's goals. Hence, there is risk associated with any attempt to intervene. However, this more active sense of the role of the facilitator is the model that has been much more fully explored in the management community and within the Focus Group tradition (Denning and Verschelden, 1993; Fern, 2001).

In the systems tradition the focus on groups might be best summarised in the work of the Systems Group at the Open University. The systems summer school taught by the group 'Experiencing Systems' (Open University, 2001) managed PSGs in a systemic manner with the following aims:

To introduce group members to one another in such a way as to enable them to learn a little about each other in a relaxed and informal setting;

to ensure that the group forms;

to heighten your awareness of group processes, and to show the value of reflecting on those processes;

to introduce ways in which teams can work together;

to introduce the idea of structuring problems by using an explicit method for doing so.

(Open University, 2001, p 7) 
The systems tradition does not seek to explore psychodynamic issues and does not directly involve the unconscious as a component of the group work.

By way of contrast, in the psychodynamic tradition there is a strong focus on the conscious and unconscious within group work rather than the outputs per se. For example, Tavistock, working from the psychodynamic tradition, have developed the 'Leicester Conference', http://www .tavinstitute.org/work/development/leicester_conference .php, which claims it:

has been running since 1957, is designed for those who are looking to develop their leadership and managerial capacity to effect change in work groups and organisations and to improve their ability to work with complex and challenging issues. Each conference is a temporary organisation consisting of a series of events which are designed to enable the exploration of different work experiences and behaviour. So, there are no presenters as such; instead the conference staff offer working hypotheses based on their experiences and understanding of what is happening in the 'here and now' in the various events. (Tavistock Website)

Linked to this tradition is 'Managing Complexity in Organisations', of the Bayswater Institute, http://bayswa terinst.org/, which claims of its conference that it helps groups:

explore the various internal and external forces which affect us, our roles and in our organisations;

design opportunities to explore the seemingly irrational and frequently unrecognised forces which may make for stress within groups and organisations;

develop ways of making such forces and their functions more explicit;

apply such understanding to the management of interdependencies and divergencies within and between groups, and to the management of 'boundaries' or interfaces with our environments;

widen the capacity for consultation, recognising the part it plays in managerial and professional competence. (Bayswater Website)

Here there is less emphasis on outputs per se and more focus on process: how the group members interact and what they learn about themselves from that interaction. As a result of this need for self-discovery, the workshop can last for much longer than may be the case under the systems/OR tradition. However, this focus on the conscious and unconscious within group work can lead to some deeper issues. This comment from a facilitator at a psychodynamic event provides an illustration:

I was acting with a colleague as a facilitator of an unstructured and leaderless group in a training event on group dynamics. Towards the end of one of their sessions the group were immersed in their discussion and I reminded them of the time that remained. At the close of the session my colleague, who had a psychodynamic background, was furious with me for making an inappropriate intervention. She said that the group had to find their own way to manage themselves and that my intervention was taking that control away from them. They had to learn to live with the consequences of their actions. I said that I regarded my role as a constructive one and that I had simply suggested that the group review its position given the limited time available. Later we used this incident to have a broader discussion of the role of facilitator in group work. Her position was that the job was to make explicit the dynamics in the group and to feed them back as issues for the group to deal with, no matter how painful and anxiety provoking the members of the group might find that. It was a 'no pain, no gain' approach to learning. I said I thought that there was plenty of learning that could go on without it necessarily being painful and that it must be possible for facilitators to point to issues in the group in a constructive way without robbing the group of its autonomy. Facilitators often have a wealth of experience and it must be part of our role to make these resources available for the group. But it is not a case of telling them what to do. It may, for example, be necessary to find a way of capturing what is happening in a way that shows it is a common feature of the way groups behave. Although this was a healthy discussion it did not resolve the differences and I was reminded that, in the psychodynamic tradition, a lot of the practice is based on the concept of a repressed unconscious and that progress is made only when what has been repressed is painfully unearthed and worked through.

Insights such as this rarely make their way into the formal academic literature, but the practitioner's quote underlines the need within the psychodynamic tradition for PSGs to find themselves while engaging in the process of problem structuring, and to do this with little regard to the pain or cost involved in such 'discovery'. The assumption is that the very process of going through the pain is ultimately positive as it will enhance the group's learning about itself and where it wants to be; they must 'learn to live with the consequences of their actions'. Thus, an appreciation of process is not just important but vital. However, whether this assumption is always the case is a matter of conjecture, and it is not inconceivable that a group going through the pain will not arrive at such a positive outcome. In other words, there is some risk.

Both psychoanalytic and systems/OR traditions have made copious use of many available tools to explore the group mind, and to attempt to enhance the productivity and value of PSG outcomes as problem solvers. However, there does appear to be an opportunity to cross-reference methods from each tradition and seek to explore means by which PSGs may have their work outcomes enhanced by understanding more about the 'how' of the group dynamic 
as well as the 'what' outcomes. In seeking to explore the 'gap' between the OR/systems thinking and practice and psychodynamic traditions, we seek also to make use of the variety of methods applied in each field and make an assessment of their relative values. Smith (2001), in concluding his review of the group work literature, called for a need to use multi-method research in developing and testing new models:

Overall, what is being suggested here is the use of multiple methods to augment the findings of singular, solitary methods such as observation. By proceeding in such a manner, future researchers should be able to uncover deeper and hidden meanings that underlie group and individual behaviour. In addition, this approach can be used in either a manner in which the various models build upon one another or in such a way that the data gathered provide deeper meaning and insight into the developmental process. (Smith, 2001, p 43)

The authors accept these points and recognise that understanding group process is important as a means of understanding the change and innovation in problem structuring that a group may promote. This is the starting point for our paper, and what follows is a description of a potential multiple method and some sense of how it has been applied in a European Union FP7 project. Our aim is to provide some insights, rather then definitive answers, into some key questions that we have already raised:

1. Is there value in being much more open and analytical about practitioner understandings of PSG situations arising from the application of multiple methods? If so then:

2. How can we make the unwritten rules and outcomes of group dynamics in problem structuring written? Indeed, open to whom? Added to all of the above is:

3. How much of any insights should be shared with those engaged in the workshop?

4. Do participants have a right to know what their facilitators think during the workshop, even if this may be interpreted as being critical?

These questions arise from our previous experience of group work over many years, and seem to be largely open to interpretation in the literature. They influenced the work we undertook in our research and are to some extent addressed in the following section. We return to them in more detail in our concluding section.

\section{TTM: a way to 'reveal' the dynamic in PSGs?}

In our research addressing the four questions set out above we have developed a method called TTM. At one level it is an extension of the Systems/OR tradition, going beyond an emphasis on group output and including a stronger sense of group dynamic. TTM is a form of multi-methodology designed for the analysis of group work 'in the round', both from internal and external perspectives, and is constructed around the understanding that group dynamic is an important factor helping to influence the nature of PSG outputs. However, as we will set out later, TTM also provides a more structured means by which the psychodynamic tradition can be practised while not diminishing or compromising the necessary passive quality of psychodynamic observation. In this sense, TTM assesses both the group's output and its process. We are concerned to monitor but not judge the type of group activity and the manner in which this activity is undertaken. Thus, we argue that TTM can be a means of hybridising the two traditions in PSG work. TTM applies, as Smith suggested, multiple methods to try to uncover deeper and hidden meanings that underlie group and individual behaviours. We have referred to aspects of the work that TTM engages with in terms of the hidden and the unwritten or 'acroamatic' - emphasising this search for the deeper and hidden (Bell and Morse, 2007a). TTM is thus an attempt to blend both the OR/systems practice traditions with elements of the psychodynamic tradition - most specifically as expounded by Bridger (2007) in his Double Task model. Our suggestion is that the Triple Task exercise can be used in a similar manner to Double Task, helping a group to 'find itself', by means of a concerted and self-scrutinised cooperative engagement.

\section{Triple task in research}

The research that provided the basis for this paper took place in six participatory workshops, in Malta, Slovakia (two workshops), Finland, Denmark and the UK during 2009/10. Each workshop took 2 days with 1 day set aside for interviews with those that took part. The work was one work package of a larger project entitled POINT-Policy Use of Indicators (contract no 217207; project website www.point-eufp7.info). The workshops employed TTM in a sequential manner. Task 1 of 'Triple Task' is a variant of the 'Imagine' participatory problem structuring methodology described by us in this journal in Bell and Morse (2007a,b), and in Bell and Morse (2008), and which in turn is a manifestation of the 'Systemic Sustainability Analysis' theoretical framework also put forward by us in Bell and Morse (2003). 'Imagine' can be regarded as an extension of 'Soft Systems Methodology' (Checkland, 1981; Checkland and Poulter, 2006). Just as in 'Soft Systems', Task 1 seeks to encourage participants to arrive at a shared understanding of 'what is' and 'what can be done' in a problem structuring context. In the project summarised here the problem to be solved was: How can the group gain a shared understanding of the use of indicators in sustainable development and sectors such as agriculture and transport? 
Triple task-steps of Task 1

Our focus and use of TTM was indicator usage in the EU, but the same process has been applied in other contexts. As with soft systems methodology (SSM), the 'Imagine' Task 1 step of TTM involves a number of steps to move from an understanding of the context, through clarification of the main issues and concerns in an action plan. In the original form of TTM as applied in POINT, Task 1 took the form of a seven-step process. A brief summary is provided in Table 1 .

1. As with SSM, the first part of Task 1 is designed to gain a shared group understanding of the context. This is achieved by means of an RP mapping exercise. All participants were involved in drawing an RP of their combined experience of the use of indicators to date. An example of RPs developed in Malta is shown as Figure 1.

2. Tasks and issues. Participants draw out major issues or problems with their combined use of indicators, as well as things that might be done to improve the situation.

3. Systems of Challenges. Participants put together tasks and issues in four or five Systems of Challenges - which are clusters of linked tasks and issues but provided with a common label in order to indicate their main, collective meaning.

4. Defining and transformation. The PSGs set out the main Beneficiaries of potential action, Implementers of action, Transformation arising from action, Assumptions behind the action, Owners or eventual action systems, and Constraints to action (BITAOC), and Identify what is required to address the challenges set out in Step 3.

5. Vision of Change. What is the vision of change the group would like to see- how might the actions set out in the BITAOC result in change?

6. Action plan. How will the group go about improving their context?

7. Develop RP scenarios for the future. Who needs to do what and when in order to achieve the vision of change?

Thus, Task 1 is 'problem structuring' very much within the systems tradition, and the role of the facilitator is to support and encourage.

Table 17 Step Process for Task 1

\begin{tabular}{lll}
\hline Element & Process/content & Outcome \\
\hline Introduction & $\begin{array}{l}\text { Introductory presentation. The ambitions of the } \\
\text { workshop }\end{array}$ & Awareness of the expectations of the workshop
\end{tabular}

Process 1: Rich Picture (RP) mapping

Process 2: Tasks and issues

Process 3: Systems of Challenges (SoCs)

Process 4: BITAOC-turning the challenge into a transformation

Process 5: Root definition of the BITAOC into a Vision of Change (VoC) statement

Process 6: Action plan the transformation - who does what when?

Process 7: Scenario map possible futures
All participants involved in drawing a RP of their combined experience of the use of indicators to date

Participants draw out major issues or problems with their combined use of indicators. Also things that might be done to improve the situation

Participants put together tasks and issues in four or five combined SoCs and provide them with catchy titles to indicate their main meaning. Participants asked to grade the SoCs in terms of their relative importance

For as many SoCs as time allows, develop them into BITAOC criteria

For as many BITAOC criteria as time allowsdevelop into a statement or VoC

For as many VoCs as time allows for: develop an outline of Who needs to do What and When in order to achieve the $\mathrm{VoC}$

For as many scenarios as time allows for: $\mathrm{RP}(\mathrm{s})$ by the group of how a better future might look
Group awareness plus shared understanding of the experience of indicators (including 'use')

The potential for focus and concentration on main shared issues and tasks

Potential for more focus and assessment of the big themes/challenges to the use of indicators

An opportunity for clarity about how things might be improved upon

Visionary statements about how things could be improved upon

An action plan of the changes that could be achieved in order to make the use of indicators more effective in decision making

At least one, but maybe a sequence of realistic views of how the future might look 


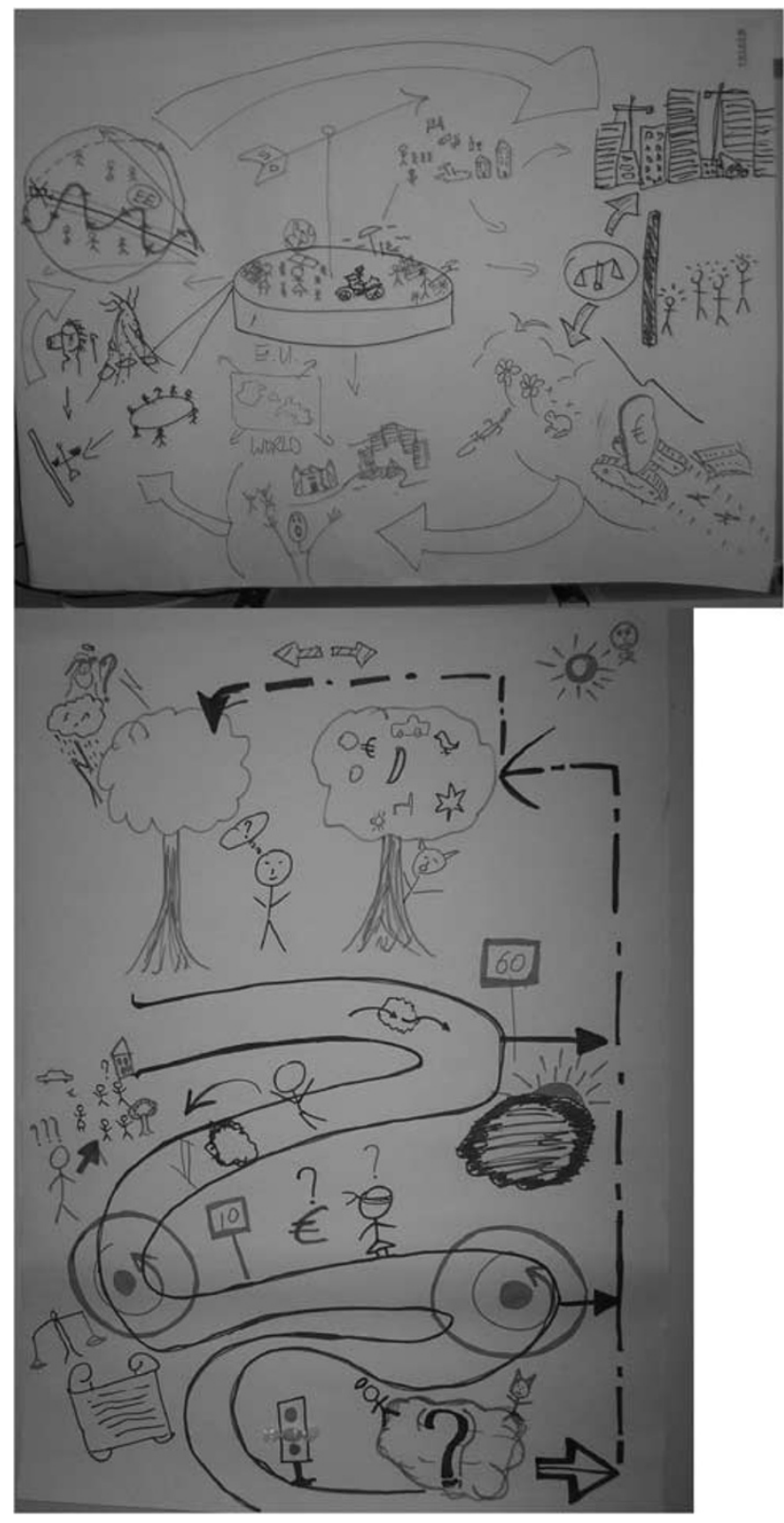

Figure 1 Rich Pictures from Malta.

\section{Triple task-Task 2}

Tasks 2 and 3 of Triple Task are separate assessments of the group performance taking place in Task 1. Both take place while Task 1 is happening. Task 2 is an external analysis of group interactions arrived at by facilitators who are not within groups. It is a reflective review of the manner in which the PSGs work using the Action Learning Cycle (including the Being, Engaging, Contextualising and Managing or BECM matrix (as shown in use by Bell, 2008). The BECM matrix is shown in Table 2. Essentially, each group is assessed by the facilitator at five stages of Task 1. The PSGs are assessed in terms of the four BECM qualities. This provides the facilitator with a sense of how the groups are working over the workshop process. An example of a BECM assessment of a group is shown in Figure 2. To understand Figure 2, a small 'amoeba' shape in the middle of the circle indicates that the facilitator considers the group to have positive BECM behaviour. A large and ragged amoeba would indicate poor behaviour. An amoeba that got smaller over the five process points of observation would indicate an improving group. This small amoeba indicates positive BECM analysis.

\section{Triple task-Task 3}

Task 3 is a self-analysis by individuals within groups of themselves and their group interaction using the Symlog (SYstem for the Multiple Level Observation of Groups) methodology. The theory and practice of Symlog has been set out in a variety of publications since its origin in 1979 (Bales et al, 1979), and some examples are Nowack (1987), Hurley (1991), Hare et al (2005) and Sjøvold (2007). Symlog has a long pedigree in research as a means of exploring the group dynamic, and has been applied in a wide range of contexts and examples, including group conflict (Becker-Beck, 2001), face-to-face versus computerbased communication (Becker-Beck et al, 2005) and health care (Cashman et al, 2004; Gfrörer et al, 2007). Symlog involves the use of a questionnaire having 26 questions designed to analyse an individual's perception of themselves, other members of the group or the functioning of the group as a whole. The durability of Symlog means that there is much experience in the collation, analysis and, perhaps more critically, the interpretation of results that arise from completion of the questionnaire. Indeed, the Symlog Consulting Group website (www.symlog.com) claims that:

The SYMLOG research base contains over 1000000 profiles drawn from applications in twelve languages, in sixty countries, on six continents.

Linked to these results, there are useful interpretive devices such as Symlog 'field diagrams' and 'ideal' group profiles that allow the categorisation of responses based upon extensive experience. Both of these visual devices help to locate people, and indeed the group to which they may belong, within a three-dimensional space of behaviour based upon the answers they give to the 26 questions of the questionnaire. Indeed, given that there is so much experience with Symlog, it is possible to identify what its practitioners refer to as 'effective' group function. The profile for any individual or group may, or may not, fall within that 'effective' range.

Symlog allows for elements of the group dynamic to be explored that would otherwise not be visible to the facilitators. With BECM the assessment can only be based upon what the facilitators can observe, but with Symlog it 
is possible to explore the dynamics that the facilitators were not privy to and could not see. The disadvantage of Symlog is that some participants can find the questions intrusive and challenging, and the answers are of course highly influenced by the 'mood' of the moment.
In the POINT project workshops the Symlog questionnaire was completed by each member of the groups at the end of each of the 2 days of the workshop. They were asked to complete two Symlog forms: one relating to themselves and one relating to the behaviours that they

Table 2 The BECM matrix

\begin{tabular}{l} 
Broad guidelines for \\
team assessment - the \\
group shows ... \\
\hline 1. That it has \\
internalised the \\
concepts/skills \\
associated with effective \\
practice - can use and \\
apply ideas in a logical \\
way_varying \\
approach in reflection \\
with context. The group \\
can adapt and change \\
approach in creative \\
ways. Learning is bi- \\
directional. Evidence of \\
realistic, astute, \\
practical judgement \\
and perception
\end{tabular}

2. A solid grasp of methods, which can be applied over a wide range of contextswithout the innovative ability to reflect imaginatively. Good, straightforward and sensible approach. Potential but needs to develop reflective capability

\section{That it has good qualities and can manage an enquiry but understanding of arguments and engaging are flawed and limited. Not wholly confident about methods}

\section{That it has adopted} an instrumentalist (line of least resistance) approach to getting through. Has difficulty contextualising approaches to changing circumstances - low to poor ability to engage reflectively

\begin{tabular}{|c|c|c|c|}
\hline $\begin{array}{l}\text { Being_respecting } \\
\text { perspectives - the group } \\
\text { is ... }\end{array}$ & $\begin{array}{l}\text { Engaging with complex } \\
\text { situations: the group } \\
\text { shows that ... }\end{array}$ & $\begin{array}{l}\text { Contextualising an } \\
\text { approach: The group } \\
\text { does ... }\end{array}$ & $\begin{array}{l}\text { Managing practice: the } \\
\text { group manages by... }\end{array}$ \\
\hline $\begin{array}{l}\text { Self-aware, aware of } \\
\text { others and ethically } \\
\text { focused. Written } \\
\text { material uses second- } \\
\text { and third-order } \\
\text { language ('I' and 'we') }\end{array}$ & $\begin{array}{l}\text { Complexity seen as } \\
\text { being within the nature } \\
\text { of relationships not } \\
\text { something } \\
\text { overwhelming 'in the } \\
\text { world'. The group } \\
\text { understands that good } \\
\text { qualities emerge from } \\
\text { reflective engagement }\end{array}$ & $\begin{array}{l}\text { Adapt concepts, } \\
\text { approach and } \\
\text { methodology to context } \\
\text { with ease, responsibility } \\
\text { and creativity }\end{array}$ & $\begin{array}{l}\text { Inviting and welcoming } \\
\text { others to join in and } \\
\text { share enquiry. The } \\
\text { group is aware of the } \\
\text { value of people sharing } \\
\text { in enquiry. They } \\
\text { appreciate the need } \\
\text { for evaluating own } \\
\text { managing. The group } \\
\text { is responsive to } \\
\text { opportunities and } \\
\text { 'environmental' } \\
\text { problems }\end{array}$ \\
\hline
\end{tabular}

Aware and sometimes self-aware. Evidence of considering ethical issues. Frequent use of ' $I$ ' and 'we' in group discourse

Aware but not really self-aware. Some use of ethical approaches.

Written material uses mainly first-order language ('it', 'them')
Complexity usually seen as being not something overwhelming 'in the world' understandable and

Some good at adapting approach to context.

Good grasp of approach and methodology

Complexity sometimes seen as being understandable and not something overwhelming 'in the world'
Generally well at adapting approach to context. Better than adequate grasp of approach and develops own methodology
Very limited awareness. Very limited thought about the ethics of an intervention as demonstrated by use of 'it' and 'them' language
Complexity usually in the world'-sometimes abstractly considered as being understandable
Sometimes prove to be able at adapting approach to context. Adequate grasp of approach - applies methods and sometime methodologies
Providing the wherewith-all for mutual and effective enquiry. It demonstrates awareness of modes of managing (for, with, or enabling others to). It acknowledges the need to be responsive to environment

Sometimes providing mutual effective enquiry and sometimes aware of different modes of managing. Some, though inconsistent acknowledgement of, and responsiveness to, the environment

Showing little but occasional thought of viability in enquiryfairly instrumentalist. Little acknowledgement of environment outside immediate managerial concerns 
Table 2 Continued

\begin{tabular}{|c|c|c|c|c|}
\hline $\begin{array}{l}\text { Broad guidelines for } \\
\text { team assessment-the } \\
\text { group shows ... }\end{array}$ & $\begin{array}{l}\text { Being_respecting } \\
\text { perspectives-the group } \\
\text { is ... }\end{array}$ & $\begin{array}{l}\text { Engaging with complex } \\
\text { situations: the group } \\
\text { shows that ... }\end{array}$ & $\begin{array}{l}\text { Contextualising an } \\
\text { approach: The group } \\
\text { does ... }\end{array}$ & $\begin{array}{l}\text { Managing practice: the } \\
\text { group manages by... }\end{array}$ \\
\hline $\begin{array}{l}\text { 5. Some reference to } \\
\text { methods but mainly an } \\
\text { instrumentalist } \\
\text { approach of the most } \\
\text { limited and basic kind. } \\
\text { No coherent logical } \\
\text { thread going through } \\
\text { work. Work full of bald }\end{array}$ & $\begin{array}{l}\text { Not aware of how the } \\
\text { self is or relates to } \\
\text { others as demonstrated } \\
\text { by limited use of 'it' and } \\
\text { 'them' language }\end{array}$ & $\begin{array}{l}\text { Complexity is always } \\
\text { 'in the world'-always } \\
\text { divorced completely } \\
\text { from different } \\
\text { perceptions including } \\
\text { that of the practitioner }\end{array}$ & $\begin{array}{l}\text { Not prove able to adapt } \\
\text { approach to context. } \\
\text { Very limited grasp of } \\
\text { approach-applies } \\
\text { methods in a simple, } \\
\text { though not incomplete } \\
\text { systematic, unreflective } \\
\text { manner }\end{array}$ & $\begin{array}{l}\text { Highly instrumentalist. } \\
\text { Little awareness of } \\
\text { different modes of } \\
\text { managing. The style } \\
\text { tends to be a narrow } \\
\text { and sketchy focus on } \\
\text { elements bound within } \\
\text { a presumed 'system' }\end{array}$ \\
\hline
\end{tabular}

and stereotypical 'this is

what you want to hear' comments but not based on learning. Repeating known and preferred ideas without thought

6. Little of reflection on behaviour. A few isolated points. Grossly flawed understanding and representation of points. Incoherent

7. No understanding of methods for reflection. Joining the dots
A tyranny. Frequent use of dogmatic assertions and no evidence at all of being self-critical
Domination and selfassertion. Possible signs of egoistic attitude permeating reports, accompanied with dogmatic assertions
Complexity is someone else's fault

Complexity is not understandable and chaos is expected
Not have any kind of grasp of systems concepts or approaches at all
Not adapt approach to context. Muddy view of any approach - square peg in round hole
Showing no awareness of different modes of managing. Nonresponsive to values, beliefs and circumstances outside the managers own sphere

Flagrant abuse of others values, beliefs and circumstances. No idea of what 'managing' involves

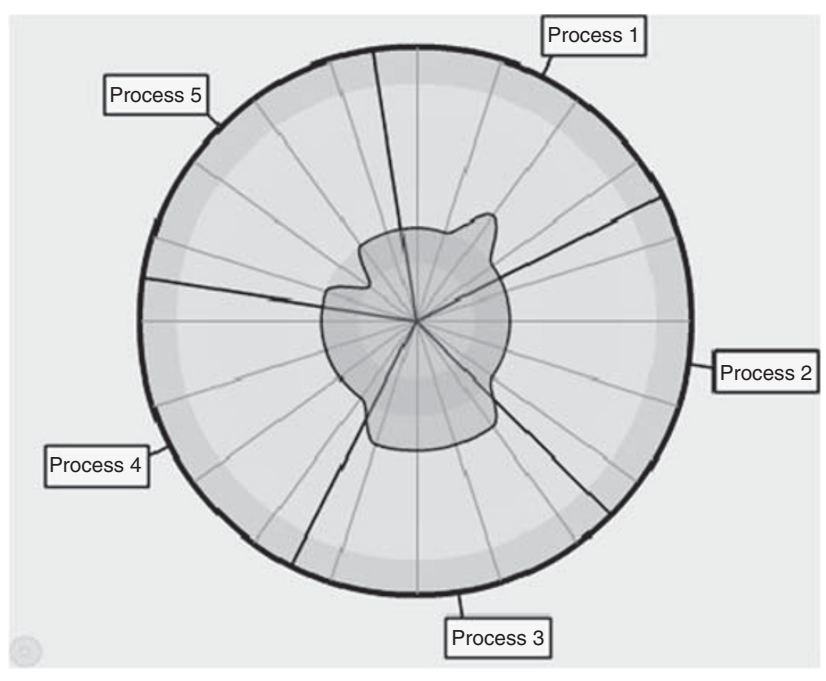

Figure 2 BECM assessment.

observed in the group during the day. These results were then mapped onto field diagrams and used to explore how close the group was to the 'effective' range.

\section{Blending the triple task}

The result of putting these three tasks together is effectively a triangulation, including a group 'problem structuring' process (Task 1) along with an analysis from the outside of the group looking in (Task 2) and from the insider of the group looking at itself (Task 3 ). Our concern remains to understand why groups may have arrived at the outputs they did.

Our analysis for the PSGs that we worked with resulted in field diagrams whereby each group could be mapped and compared to others in terms of the three tasks. The TTM field diagrams we created have a superficial similarity to the Symlog field diagrams mentioned earlier, but were designed to relate the quality of the problem structuring (primarily assessed by scoring of the various outputs of Task 1) - the horizontal axis - to the quality of the group dynamic (vertical axis and size/shading of circles). Given the space limitation it is not necessary to go into all the methodological detail here, but Figure 3 provides an example of a TTM field diagram for a number of groups engaged in the POINT project. The horizontal axis 
represents the quality of the Task 1 outputs (good quality to the right and poor quality to the left) and the vertical axis is the Symlog score for each group, or more accurately the degree of deviation of the group from the 'effective' range. A lower degree can be interpreted as 'good' group behaviour (top of the TTM Field Diagram) while a high degree of deviation can be regarded as 'poor' group function (bottom of the TTM field diagram). The key feature of the plots in Figure 3 is the clustering of some of the groups; for example, those from Denmark and Finland are clustered towards the bottom right-hand quadrant, equating to good-quality Task 1 outputs and poor group dynamic. Thus, the results suggest that good-quality outputs were achieved even when the group function was perceived by the members of the groups as being quite poor. This would appear to be counterintuitive as, after all, one would expect good quality outputs to be associated with 'effective' group function. The reason for this became clear during interviews after the workshop. The relatively long and extensive experience the participants had with indicators ensured that they all had a contribution to make, and discussions could become quite heated as a result. People could draw upon direct experience; differences of opinion may be strongly held, and hence the

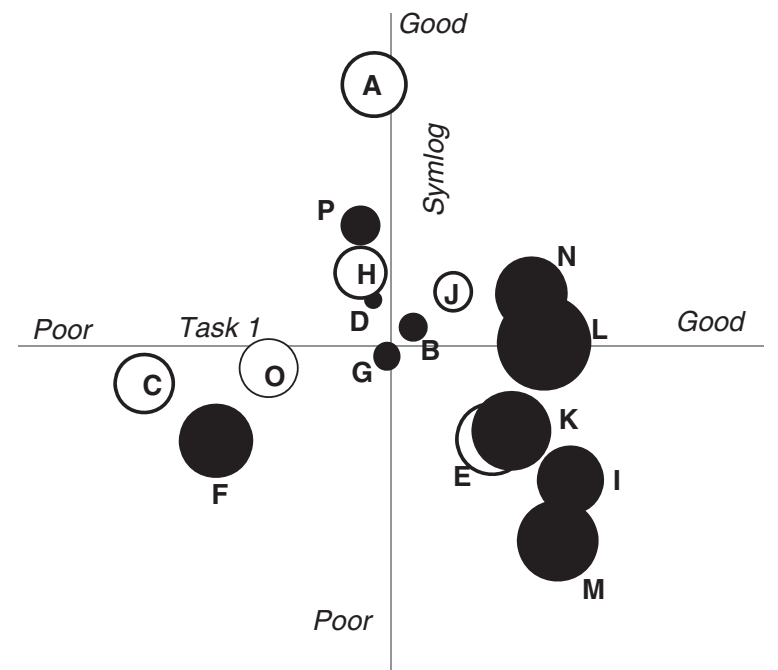

Figure 3 Example of a Triple Task field diagram.

The field diagram is based on the results of a Triple Task process with groups in the POINT project. Letters denote results from different groups: $\mathrm{A}, \mathrm{B}=$ Malta, C, D, E, F, G, $\mathrm{H}=$ Slovakia, I, $\mathrm{J}, \mathrm{K}=$ Finland, $\mathrm{L}, \mathrm{M}, \mathrm{N}=$ Denmark and $\mathrm{O}$, $\mathrm{P}=\mathrm{UK}$. The vertical axis represents the deviation of each group from the 'ideal' Symlog group profile, so that the top of the axis equates to 'good' group function while the bottom of the axis equates to 'poor' group function. The horizontal axis is a subjective assessment (via 'scoring') of the analysis undertaken by each of the groups, with 'poor' quality of analysis to the left and 'good' quality to the right. The size of each circle and whether it is filled or not is related to the BECM score over the workshop. perception of friction experienced by the group members. But at the same time this combined experience generated some high-quality analyses and novel insights. Therefore, the field diagram is not an end in itself, but is meant to provide clues that can be followed up within discussions and interviews. But the key is that it allows workshop facilitators to get a better sense as to why groups differ in their analyses. Thus, rather than leave groups to discover themselves in their own way and time, it is possible via TTM to provide some tools to help with this. In addition, it is possible to derive explanatory factors behind the outputs created by the groups. Thus far, our initial observations regarding the four questions are as follows:

Q1 Is there value in being much more open and analytical about practitioner understandings of PSG situations arising from the application of multiple methods?

The TTM approach allows for three reviews: Task 1, a review of a group doing a systemic process; Task 2, a review 'outside in' (from the facilitator) of the group's work; and Task 3, 'inside out' (from the individual group member's perspective), to be contained in the field diagram as shown in Figure 3. Our reflection is that the process of review is enriching and instructive, as we have set out in Figure 3. The Task 2 observation of a poor or struggling group with a problematic dynamic (eg maybe shouting or apathy) when cross-referenced with Task 3, inside out observations, often helps to clarify the meaning of the issues and to triangulate around the possible causes. This can result in a contestable but nonetheless evidential basis for the observations among both the facilitators and the group members. In the form of TTM applied in the POINT project, it was the facilitators who gained from this deeper understanding and thus could use it to better appreciate differences in group output. The knowledge can also be used, of course, to help the facilitator with subsequent workshops.

Q2 How can we make the unwritten rules and outcomes of group dynamics in problem structuring written? Indeed, open to whom?

Even within the output of Task 1 of TTM this occurs. The RP exercise is, as has been noted in other literature, revealing of insight and underlying story. The RP often acts as a means to externalise individual and group anxiety, and to allow the hidden, occluded and acroamatic to be talked about. In Figure 1 the second RP shows a clear 'route' for the PSG. However, with the first picture the weather vein points in moving directions and the issues for the group swirl. Tasks 2 and 3 provide more means to express and record behaviour that is not evidently described or consciously reflected upon by the group itself, but in TTM as it is currently constructed, the 'unwritten' 
remains unknown to the group. As currently understood, TTM in the mode applied (what we refer to as Mode 1 or M1) is a device held and applied by a facilitator (or facilitators) with minimal feedback on process issues to the group. However, if we want the group to own its process as well as its outcomes then this is an issue for the authors, and has provided the catalyst for the development of another version of TTM, which we refer to as Mode 2 (M2) to distinguish it from the original form, which can be called M1. Such an innovation would require the group to own the entire process, to specify that group members undertake and lead in each of the three tasks and feedback the reflections of each in a comprehensive manner to the group. In effect, M2 of TTM provides a set of tools by which groups can undergo a self-analysis rather than work it all out for themselves. This is described in more detail in the final section.

Q3 How much of any insights should be shared with those engaged in the workshop?

This is really a subset of the issue dealt with in the prior point. Within TTM in its M1 format, the insights of the group are highlighted by the facilitator and may be fed back to the group in a narrative and unstructured manner, although this did not take place with the POINT workshops. The feedback provided by the facilitator can relate to a range of items, some of which the group might think of as being 'good', such as some unique insights into confusing areas, or 'bad', for example group domination by a minority, long periods of inactivity or apparent inertia, or apparent steady but unremarkable outcomes of Task 1 processes. The issue for M1 of TTM is whether and how much to feedback without in some way compromising the activity of the group. After all, while there is some cognisance taken of group function, M1 TTM is still very much within the OR tradition. Generally, the use of TTM has been to gather information from groups regarding their combined reaction to certain issues and how they would solve the 'problems' that they identify-for example, the misuse or non-use of indicators in sustainable development policy. Feedback to these groups is usually directly related to enhancing the group's activity (from the point of view of the facilitator) in terms of achieving insights and breakthroughs in thinking. In this applied use of TTM, the facilitator might be thought to be less likely to share insights, which could lead to group dysfunction or breakdown. After all, the goal of the facilitator is to complete the analyses. However, if a group is proving to be confident and able or in need of a 'nudge' the facilitator might use controversial insights in feedback sessions in order to provoke reaction. In either case, reserving information to support group function or sharing feedback to provoke group reaction, the sharing of insights in M1 TTM could be said to be idiosyncratic and unstructured.
Q4 Do participants have a right to know what their facilitators think during the workshop, even if this may be interpreted as being critical?

This question now emerges as the culmination of the logical outcomes of the previous three, and also provides the development of the case for M2 TTM. In the POINT project the results were not fed back to the participants in any formal sense, but they did form the basis for a series of 'debrief' interviews that were held after the event. Thus, when the assessments of the group, via BECM, Symlog or both, suggested friction, then this provided avenues for exploration, especially in terms of how it might have influenced the group analysis within Task 1. Participants at that stage often acknowledged problems in the dynamic, but this was after the event and not during it. Thinking back to the reflection from the psycho-dynamists set out in the first part of this paper, there is no pain without gain. According to this mode of group work, the feedback from the facilitator to the group needs to be as full and open and honest as possible. The psychodynamic tradition would seem to require this kind of feedback to allow the group to grow and learn, but for the most part this is encouraged by self-discovery rather than a facilitator intervening to provide their 'outside in' views. The various strands of the systems tradition have been argued to be possibly less organised in handling of feedback. For example, it can be structured and planned or completely absent (Ackermann, 1996; Papamichail et al, 2007). In M1 TTM, the feedback to participants tends to arise from the interpretation of the facilitator and his/her identification of what would make the group's outcomes more interesting for the research results. The approach could be described as being instrumentalist from the group's perspective, and is located firmly within the systems tradition. Again, this draws us to the suggested M2 TTM. In this mode, the actors of the group would have access to all the findings of the three tasks as they would be responsible for doing all of them and thus would have the discretion to act on what they discover or not. Our main reflection is that TTM 'uncovers' a wide range of information on group process 'on task' from Task 1, on the group's dynamic from the outside observation (Task 2) and from the individual (Task 3). The coherent and systemic integration of these three sources of information 'could' be available to groups. M2 TTM might be an interesting way of achieving this, and thus can almost be seen as located within the psychodynamic tradition, but with tools to help facilitate the self-analysis.

\section{Potential prizes for problem structuring with groups}

TTM was initially developed to enable researchers to understand better why and how groups arrive at the 
outcomes they do. In the process of undertaking the POINT project, new questions and properties have arisen from the application of the method, and, from this perspective, it is pertinent to ask: To what extent can Tasks 2 and 3 be useful to groups, applied in M1 or M2, why and to whom?

For facilitators, the method can be a means by which experience can be structured. Tasks 2 and 3 allow for more nuanced and formal comparisons with the outputs from Task 1 that take the learning out of the casual and anecdotal and provide for Smith's augmentation of multiple methods. Thus, facilitators can learn more about the groups they work with (eg the value of roles, the relative weight of seniority, observations around the importance of gender to decision making, etc) and thereby enhance the prospects of future success. Such 'facilitator learning' is clearly helpful over the longer term, and thus extends far beyond the life of a current workshop. In effect, TTM M1 uses 'present group' learning for 'future group' enhancement rather than necessarily providing benefits for the present groups engaged in the workshop. It is beneficial for the facilitator and future groups he/she will work with, and providing every group accepts that premise then they are benefitting from those that went before.

Building on this, it may be possible for the facilitator to use the information to help him/her manage the groups within the workshop. This is especially the case with the BECM tool as it can be applied in 'real time', but may also be the case with Symlog if, as with the POINT project, the workshop extends over a couple of days and there is a natural break that allows the facilitator time to collect and process the questionnaires. Indeed, going one step further, is it practically possible to feedback the results of Tasks 2 and 3 to the current group. And what may be the result? Our preliminary reflection is that it can be possible using a variety of potential mechanisms and aids. But what would it serve? Will a group benefit from being critiqued or praised in terms of its functioning? There is also an issue here of the longevity of the group and its durability over time. Clearly, if the group is a transient structure that has existed for the duration of the workshop then some of the benefits will evaporate as soon as the workshop is over. That is not to say that individuals will not take something away with them from the process - they may well indeed gain something from the experience. For a group of people that will continue to relate to each other, even at a distance, once the workshop is over then any benefits that accrue from an analysis of their function may potentially be far greater and long-lived. There is much scope here for more research. We suggest that M2 TTM opens the prospect of 'present group' enhancement-providing opportunities for the group to share deep experiences, usually hidden or, conversely, brutally exposed by practitioners from the systems and psychodynamic traditions, respectively. This could be rewarding, but equally it could be the cause of greater friction. There are many unknowns here, and there is certainly scope for more research to explore the impacts of M2 TTM.

There is an ethical element to the revealing of the hidden, as - after all - the groups that take part in TTM and thus generate the insights under its three components should conceivably have a right to know what they say about themselves and what others may think. We would very much welcome views on this point, but it is conceivable that feeding back the results of Tasks 2 and 3 in 'real time' to a group could have all sorts of impacts, from enhancement to destruction. In between these extremes, it may have no effect at all.

These are deep waters and traditions vary in their conclusions. For some the immediate feeding back of the results of Tasks 2 and 3 is ultimately always positive - even if it is destructive - as it helps the group learn about itself. A 'warts and all' exposé is seen in the psychodynamic tradition as ultimately cathartic even if there is much pain along the way. The nuanced revelation of group dynamic - discovered by members of the group and interpreted in turn by all group members-provides an opportunity for further group development in a more constructive way. Whether this is always the case is a moot point. Do groups always benefit from such self-analysis or can it result in a greater schism? This is another complex question, and the obvious response would be to design research to explore the impact of TTM on groups. But this would be a 'non-trivial' challenge (to use a term from quantum physics) given that groups vary so widely. Even the dynamic of a single group varies over time. In the debrief sessions held at the end of each POINT workshop, respondents were asked about their group dynamics, largely as a way of calibrating the BECM scoring, but if TTM had been undertaken in M2 then it might have been possible to ask the respondents about the impact that such feedback might have had on the group. No doubt this could be an interesting and fruitful strand of research.

Finally, it must be stressed that we fully acknowledge the role of the facilitator and the power that is invested in that position, be it via TTM in Modes 1 or 2. TTM does not in itself provide a buffer or antidote for bad facilitation; groups can still be influenced by the facilitator and directed down roads that they may not have thought of going down. TTM is by no means a panacea.

Acknowledgements — The research leading to the discussion presented in this paper was funded by the European Commission's Seventh Framework Programme (FP7/2007-2013) under grant agreement $n^{\circ}$ 217207 (POINT project, www.point.pb-works.com). The authors express their gratitude to all of their colleagues in POINT, but especially Louis Cassar and Liz Conrad (Malta), Zuzana Valkovcova and Daniela Babicova (Slovakia), Jari Lyytimäki and Kautto Petrus and (Finland), Henrik Gudmundsson (Denmark), Markku Lehtonen (UK), Tom Bauler and Léa Sébastien (Brussels). Without their support the Triple Task workshops would not have been possible. 


\section{References}

Ackermann F (1996). Participants' perceptions on the role of facilitators using group decision support systems. Group Decision and Negotiation 5(1): 93-112.

Andersen DF and Richardson GP (1997). Scripts for group model building. System Dynamics Review 13(2): 107-129.

Avison DE, Golder P and Shah H (1992). Towards an SSM toolkit: Rich picture diagramming. European Journal of Information Systems 1(6): 397.

Bales R, Cohen S and Williamson A (1979). Symlog: A System for the Multiple Level Observation of Groups. Free Press: New York.

Bateson G (1972). Steps to an Ecology of Mind: Collected Essays in Anthropology, Psychiatry, Evolution and Epistemology. University of Chicago Press: Chicago.

Becker-Beck U (2001). Methods for diagnosing interaction strategies: An application to group interaction in conflict situations. Small Group Research 32(3): 259-282.

Becker-Beck U, Wintermantel M and Borg A (2005). Principles of regulating interaction in teams practicing face-to-face communication versus teams practicing computer-mediated communication. Small Group Research 36(4): 499-536.

Beise C, Neiderman F and Beranek P (1999). Group facilitation in a networked world. Group Facilitation 1(1): 33-44.

Bell S (2008). Systemic approaches to managing across the gap in the public sector: Results of an action research programme. Systemic Practice and Action Research 21(3): 227-240.

Bell S and Morse S (2003). Learning from experience in sustainability. The 2003 International Sustainable Development Research Conference, University of Nottingham, UK.

Bell S and Morse S (2007a). Problem structuring methods: Theorizing the benefits of deconstructing sustainable development projects. Journal of the Operational Research Society 58(5): $576-587$.

Bell S and Morse S (2007b). Story telling in sustainable development projects. Sustainable Development 15(2): 97-110.

Bell S and Morse S (2008). Sustainability Indicators: Measuring the Immeasurable. Earthscan: London.

Bion WR (1961). Experiences in Groups and Other Papers. Basic Books: New York.

Bostrom R, Anson R and Clawson V (1993). Group facilitation and group support systems. In: Jessup L and Valacich J (eds). Group Support Systems: New Perspectives. Palgrave Macmillan: New York.

Bridger $H$ (2007). The consultant and the consulting process. London, The Bayswater Institute: Handout at the Midhurst Working Conference.

Campbell Williams M (1999). Rich pictures on the path towards systemic being. Systems Research and Behavioural Science 16(4): 369

Carrizosa A (2002). Rich pictures, metaphors and stories as mechanisms to improve collective actions. In: Castell A, Gregory A, Hindle G, James M and Ragsdell G (eds). Synergy Matters. Kluwer Academic/Plenum Publishers: New York, pp. 43-48.

Cashman S, Reidy P, Cody K and Lemay C (2004). Developing and measuring progress toward collaborative, integrated, interdisciplinary health care teams. Journal of Interprofessional Care 18(2): 183-196.

Checkland P (1981). Systems Thinking, Systems Practice. Wiley: Chichester.

Checkland P and Poulter J (2006). Learning for Action: A Short Definitive Account of Soft Systems Methodology, and Its Use, Practitioners, Teachers and Students. John Wiley and Sons Ltd: Chichester.
Denning $\mathbf{J}$ and Verschelden C (1993). Using the focus group in assessing training needs: Empowering child welfare workers. Child Welfare 72(6): 569-580.

Fern EF (2001). Advanced Focus Group Research. Thousand Oaks, USA: Sage.

Fisher BA (1970). Decision emergence: Phases in group decisionmaking. Speech Monographs 37(1): 53-66.

Franco LA and Montibeller G (2010). Facilitated modelling in operational research. European Journal of Operational Research 205(3): 489-500.

Franco LA and Rouwette EAJA (2011). Decision development in facilitated modelling workshops. European Journal of Operational Research 212(1): 164-178.

Gersick C (1991). Revolutionary change theories: A multilevel exploration of the punctuated equilibrium paradigm. Academy of Management Review 16(1): 10-36.

Gfrörer R, Bernard U, Schaper C, Bauer M and Schüpfer GK (2007). Role expectations of various professional groups in the operating theatre. Anaesthesist 56(11): 1163-1169.

Hare AP, Sjøvold E, Baker HG and Powers J (eds) (2005). Analysis of Social Interaction Systems. Symlog Research and Applications. University Press of America: Lanham (Maryland).

Harmon J and Rohrbaugh J (1990). Social judgment analysis and small group decision making: Cognitive feedback effects on individual and collective performance. Organizational Behavior and Human Decision Processes 46(1): 34-54.

Hurley JR (1991). Self-acceptance, acceptance of others, and SYMLOG: Equivalent measures of the two central interpersonal dimensions? Journal of Clinical Psychology 47(4): 576-582.

Huxham C and Cropper S (1994). From many to one - and back. An exploration of some components of facilitation. Omega 22(1): 1-11.

Lewin K (1947). Frontiers in group dynamics. Human Relations 1(2): 5-41.

Lewis PJ (1992). Rich picture building in the soft systems methodology. European Journal of Information Systems 1(5): 351-360.

Maturana H (1997). Knowing and Being. Open University: Milton Keynes, UK.

Maturana HR and Varela FJ (1992). The Tree of Knowledge: The Biological Roots of Human Understanding. Shambhala: Boston.

McFadzean E and Nelson T (1998). Facilitating problem-solving groups: A conceptual model. Leadership and Organization Development Journal 19(1): 6-13.

Mingers J and Rosenhead J (2004). Problem structuring methods in action. European Journal of Operational Research 152(3): 530-554.

Morgan BB, Salas E and Glickman AS (1994). An analysis of team evolution and maturation. The Journal of General Psychology 120(3): 277-291.

Morton AF, Ackermann F and Belton V (2007). Problem structuring without workshops? Experiences with distributed interaction within a PSM process. Journal of the Operational Research Society 58(5): 547-556.

Nowack W (1987). SYMLOG as an instrument of internal and external perspective taking-construct-validation and temporal change. International Journal of Small Group Research 3(2): 180-197.

Nutt PC (2002). Why Decisions Fail: Avoiding the Blunders and Traps That Lead to Debacles. Berrett-Koehler: San Francisco.

Open University (2001). TXR248 Experiencing Systems: Residential School Student Handbook. Open University: Milton Keynes.

Papamichail KN, Alves G, French S, Yang JB and Snowdon R (2007). Facilitation practices in decision workshops. The Journal of the Operational Research Society 58(5): 614-632.

Phillips LD and Phillips MC (1993). Facilitated work groups: Theory and practice. The Journal of the Operational Research Society 44(6): 533-549. 
Pidd M (1988). From problem-structuring to implementation. The Journal of the Operational Research Society 39(2): 115-121.

Robinson S (2001). Soft with a hard centre: Discrete-event simulation in facilitation. The Journal of the Operational Research Society 52(8): 905-915.

Rosenhead J (2006). Past, present and future of problem structuring methods. The Journal of the Operational Research Society 57(7): 759-765.

Sims D, Eden C and Jones S (1981). Facilitating problem definition in teams. European Journal of Operational Research 6(4): $360-366$.

Sjøvold E (2007). Systematizing person-group relations (SPGR): A field theory of social interaction. Small Group Research 38(5): 615-635.
Smith G (2001). Group development: A review of the literature and a commentary on future research directions. Group Facilitation (3): $14-45$.

Taket A (2002). Facilitation: Some contributions to theorising the practice of operational research. The Journal of the Operational Research Society 53(2): 126-136.

Tuckman BW (1965). Development sequence in small groups. Psychological Bulletin 63(6): 384-399.

Tuckman BW and Jensen MA (1977). Stages of small-group development revisited. Group Organisational Studies 2(4): 419-427.

Received September 2010; accepted August 2012 after four revisions 